Eur. J. Clin. Chem. Clin. Biochem.

Vol. 31,1993 , pp. $217-220$

(C) 1993 Walter de Gruyter \& Co. Berlin - New York

\title{
Decreased Activation of Lecithin : Cholesterol Acyltransferase by Glycated Apolipoprotein A-I
}

\author{
By C. Calvo ${ }^{1}, N$. Ulloa ${ }^{1}, R$. Del Pozo ${ }^{1}$ and C. Verdugo ${ }^{2}$ \\ 1 Departamento de Bioquimica Clínica e Immunología, Facultad de Farmacia \\ ${ }^{2}$ Departamento de Medicina, Facultad de Medicina \\ Universidad de Concepción, Concepción, Chile
}

(Received February 18/December 17, 1992)

\begin{abstract}
Summary: Non-enzymatic glycation of plasma proteins may contribute to the excess risk of developing atherosclerosis in patients with diabetes mellitus. Glycated apolipoprotein A-I isolated from diabetic subjects was tested in vitro for its ability to activate lecithin : cholesterol acyltransferase, the principal cholesterolesterifying enzyme in plasma. Activation by glycated apolipoprotein A-I was significantly lower at all concentrations than the activation by normal apolipoprotein A-I. Linear regression analysis of the kinetic data shows that the ratio app $\mathrm{V}_{\max } / \mathrm{app} K_{\mathrm{m}}$ was significantly lower $(\mathrm{p}<0.01)$ for glycated apolipoprotein AI $(0.29 \mathrm{nmol} \cdot 1 / \mathrm{h} \cdot \mu \mathrm{mol})$ than for normal apolipoprotein A-I $(0.78 \mathrm{nmol} \cdot 1 / \mathrm{h} \cdot \mu \mathrm{mol})$. Because lecithin : cholesterol acyltransferase provides a driving force in reverse cholesterol transport by esterifying the cellular cholesterol removed by $\mathrm{HDL}$, it is tempting to postulate that this abnormal activation may be associated with a reduction in reverse cholesterol transport and associated with the accelerated development of atherosclerosis in diabetic patients.
\end{abstract}

\section{Introduction}

Apolipoprotein A-I is the major protein constituent of human high density lipoproteins (HDL). The protein contains 243 amino acid residues and its primary structure is known (1). The principal physiological functions of apolipoprotein A-I are:

1) interaction with lipids in the surface of high density lipoprotein, thereby ensuring the structural cohesion of HDL particles, and

2) activation of the enzyme lecithin : cholesterol acyltransferase (2), which is responsible for the esterification of cholesterol in human plasma.

Several genetically determined variants of apolipoprotein A-I have been described in the human population and the effects of these mutations on the apolipoprotein functions have been tested. The variant $\left(\right.$ Lys $\left._{107 \rightarrow 0}\right)$ in which lysine at residue 107 is deleted have been proved to have a decreased association with high density lipoprotein (3) and a defective ability to activate lecithin: cholesterol acyltransferase (4). Another variant, (Pro ${ }^{143} \rightarrow \mathrm{Arg}$ ), in which proline143 is substituted by arginine is a poorer activator of lecithin : cholesterol acyltransferase than is normal apolipoprotein A-I (5).

Post-translational modifications of apolipoprotein A-I may also alter the function of this apolipoprotein. We have previously reported that apolipoprotein A-I undergoes a non-enzymatic glycation in diabetic subjects (6) and that this modification alters its selfassociation and lipid binding properties in vitro (7). More recently, we have shown that the non-enzymatic glycation of apolipoprotein A-I diminishes its association with high density lipoprotein in vivo (8).

In this report we document that glycated apolipoprotein A-I purified from the plasma of diabetic subjects is deficient in its ability to activate lecithin : cholesterol acyltransferase in vitro. 


\section{Materials and Methods}

Purification of apolipoprotein A-I and glycated apolipoprotein A-I

High density lipoprotein was isolated from pooled fresh nondiabetic and diabetic human plasma by sequential ultracentrifugation in the density range $1.063-1.20 \mathrm{~kg} / \mathrm{l}(9)$. $\mathrm{HDL}$ was delipitated with ether: ethanol $\left(3+1\right.$ by vol.) at $4{ }^{\circ} \mathrm{C}$ and the apolipoproteins were fractionated on a Sephadex $\mathrm{G} 150$ column (10). Glycated apolipoprotein A-I was purified from the apolipoprotein A-I of diabetic patients by affinity chromatography in aminophenylboronic acid (Affi Gel 601) (7). All apolipoprotein preparations yielded a single band on SDS-polyacrylamide electrophoresis. Absence of other posttranslational modifications of apolipoprotein A-I and glycated apolipoprotein A-I was confirmed by amino acid analysis. Glycated apolipoprotein A-I contains $1-2$ glucose molecules per apolipoprotein A-I molecule.

\section{Purification of lecithin : cholesterol acyltransferase}

Lecithin : cholesterol acyltransferase was prepared as described previously (11). Briefly, fresh human plasma was ultracentrifuged at $\mathrm{d}=1.23 \mathrm{~kg} / 1$ for $48 \mathrm{~h}$ at $45000 \mathrm{~min}^{-1}$ in a Ti 50 rotor at $10^{\circ} \mathrm{C}$. The clear middle zone between the floating lipoproteins and the sedimenting plasma proteins was aspirated, dialysed and chromatographed on a column containing DEAE cellulose. Fractions containing lecithin : cholesterol acyltransferase activity were precipitated with ammonium sulphate and butanol and chromatographed on a Sephadex G 100 column. The purity of this enzyme fraction was assessed by polyacrylamide gel electrophoresis in $10 \mathrm{~g} / \mathrm{l}$ sodium dodecyl sulphate.

\section{Substrates}

Micellar, discoidal substrates containing $2843 \mu \mathrm{mol} / \mathrm{l}$ of 1-palmitoyl-2-oleoyl-sn-glycero 3-phosphorylcholine, $125 \mu \mathrm{mol} / 1$ of free cholesterol, $42 \mathrm{MBq} / \mathrm{l}$ of $\left[{ }^{3} \mathrm{H}\right]$ cholesterol and various $(3.5$, $7.0,14.0,21.0,28.9$, and 35.0$) \mu \mathrm{mol} / 1$ of apolipoprotein A-I or glycated apolipoprotein A-I, were prepared by the sodium cholate dialysis method (12).

The molar ratios in the micellar discoidal substrates were:

\begin{tabular}{llll}
\hline $\begin{array}{l}\text { Apolipo- } \\
\text { protein A-I } \\
\text { in the complex } \\
(\mu \mathrm{mol} / \mathrm{l})\end{array}$ & $\begin{array}{l}\text { Phospho- } \\
\text { lipid : }\end{array}$ & $\begin{array}{l}\text { Chol- } \\
\text { esterol : }\end{array}$ & $\begin{array}{l}\text { Apolipo- } \\
\text { protein }\end{array}$ \\
\hline 3.5 & 706 & 35 & 1 \\
7.0 & 706 & 35 & 2 \\
14.0 & 706 & 35 & 3 \\
21.0 & 706 & 35 & 4 \\
28.0 & 706 & 35 & 5 \\
35.0 & 706 & 35 & 6 \\
\hline
\end{tabular}

Assay of the lecithin : cholesterol acyltransferaseactivating property of apolipoprotein A-I and glycated apolipoprotein A-I

Eighty $\mu$ l of substrate, $20 \mu$ l of 2-mercaptoethanol, $10 \mu \mathrm{l}$ of buman serum albumin $(50 \mathrm{~g} / \mathrm{l})$ and $140 \mu \mathrm{l}$ of Tris- $\mathrm{HCl} 10$ $\mathrm{mmol} / \mathrm{l}, \mathrm{pH} 7.4$ were preincubated in a shaking water bath at $37^{\circ} \mathrm{C}$ for $60 \mathrm{~min}$. The reaction was initiated by addition of $50 \mu \mathrm{l}$ of lecithin : cholesterol acyltransferase $(0.30 \mathrm{~g} / \mathrm{l})$ and continued for $30 \mathrm{~min}$ under the same conditions. The reaction was stopped by the addition of $0.5 \mathrm{ml}$ of methanol. The methanol-containing incubation mixture was extrated with $1 \mathrm{ml}$ of hexane. Cholesteryl esters were separated from free cholesterol by silica gel column chromatography (elution with diethyl ether : hexane $(1+6$, by vol. $)$.

The labelled cholesteryl esters were cqllected, mixed with $5 \mathrm{ml}$ of scintillation cocktail and the radioactivity was measured in a liquid scintillation analyser, Packard 1600 TR. Blanks without enzyme were run in parallel. All the experiments were performed in duplicate. The precision of the method was $9.6 \%$, as expressed by the coefficient of variation.

The activity of lecithin : cholesterol acyltransferase was calculated from the specific radioactivity of cholesterol and expressed as nmol of cholesterol ester formed per hour. Linear regression analysis was used to obtain the apparent (app) kinetic constants: app. $\mathrm{V}_{\max }$, app. $K_{\mathrm{m}}$, and app. $\mathrm{V}_{\max } /$ app. $K_{\mathrm{m}}$.

\section{Results}

Apolipoprotein A-I and glycated apolipoprotein A-I were individually tested for their ability to activate lecithin : cholesterol acyltransferase in vitro.

Concentration-dependent, saturable activation of the enzyme reaction was observed for both the apolipoprotein A-I and the glycated apolipoprotein A-I. The results of the activator saturation experiments were analysed by the double reciprocal plot acc. to Lineweaver-Burk using normal Michaelis-Menten kinetics.

As shown in figure 1 , the activation of esterification by glycated apolipoprotein A-I was significantly lower at all concentrations than that obtained by apolipoprotein A-I.

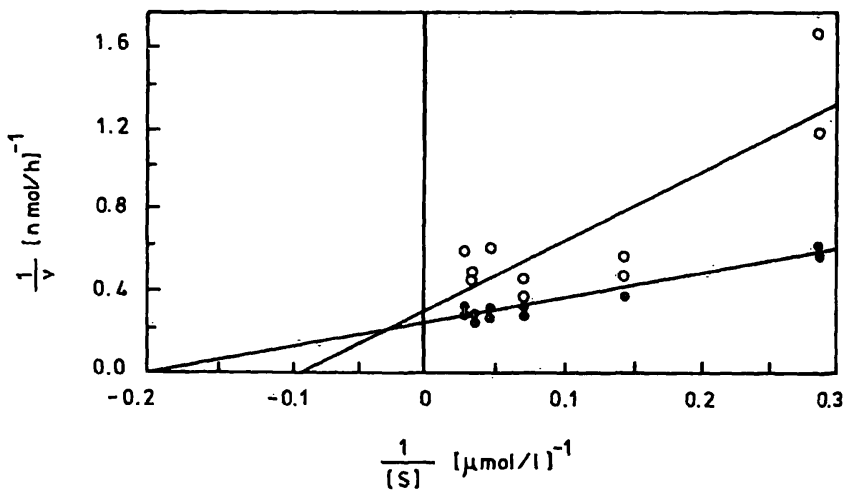

Fig. 1. Lineweaver Burk plots giving the reciprocal initial velocity of cholesterol esterification $\left(1 / v_{0}\right)$ as a function of the reciprocal substrate concentration, apolipoprotein A-I (O) and glycated apolipoprotein A-I (৫) (1/[S]). Lecithin : cholesterol acyltransferase activity was assayed at $37^{\circ} \mathrm{C}$ by measuring the formation of $\left[{ }^{3} \mathrm{H}\right]$ cholesterol esters from different liposomes, containing various amounts of apolipoprotein A-I or glycated apolipoprotein A-I. The reaction was initiated by addition of $50 \mu \mathrm{l}$ of lecithin : cholesterol acyltransferase and stopped after $30 \mathrm{~min}$ by adding $0.5 \mathrm{ml}$ of methanol.

Regression equations:

Apolipoprotein A-I:

$\frac{1}{v}=(3.462 \pm 0.524) \frac{1}{[\mathrm{~S}]}+0.320$

Glycated apolipoprotein A-I.

$\frac{1}{v}=(1.279 \pm 0.019) \frac{1}{[S]}+0.241$ 
Tab. 1. Apparent kinetic constants for the micellar complexes

\begin{tabular}{llllc}
\hline & $\begin{array}{l}\text { Correlation } \\
\text { coefficient }\end{array}$ & app. $\mathrm{V}_{\max }$ & app. $\mathrm{V}_{\max } /$ app. $K_{\mathrm{m}}$ & app. $K_{\mathrm{m}}$ \\
\hline & & $\mathrm{nmol} / \mathrm{h}$ & $\mathrm{nmol} \times 1 / \mathrm{h} \times \mu \mathrm{mol}$ & $\mu \mathrm{mol} / 1$ \\
Apolipoprotein A-I $(\mathrm{n}=12)$ & 0.95 & 4.14 & 0.78 & 5.29 \\
Glycated apolipoprotein A-I $(\mathrm{n}=11)$ & 0.85 & 3.13 & 0.29 & 10.82 \\
\hline
\end{tabular}

From lincar regression analysis of kinetic data as shown in figure 1 app. $\mathrm{V}_{\max }$ is the reciprocal of the $y$-intercept; app. $K_{\mathrm{m}} / \mathrm{app}$. $\mathrm{V}_{\max }$ is the slope of the line; and app. $K_{\mathrm{m}}$ is calculated from the other two quantities. The ratio app. $\mathrm{V}_{\max } /$ app. $K_{\mathrm{m}}$ was significantly lower for glycated apolipoprotein $(\mathrm{p}<0.01)$ using the Student's t-statistical test.

Table 1 gives the results from the linear regression analysis of the kinetic data: correlation coefficients, apparent $\mathrm{V}_{\max }$, apparent $K_{\mathrm{m}}$ and app. $\mathrm{V}_{\max } / \mathrm{app} . K_{\mathrm{m}}$ quantities. The app. $V_{\max } / a p p . K_{m}$ of glycated apolipoprotein A-I differs significantly from that of normal apolipoprotein A-I $(p<0.01)$.

\section{Discussion}

The present study indicates that glycated apolipoprotein A-I isolated from diabetic subjects is deficient in activating lecithin : cholesterol acyltransferase in vitro.

Information is very limited on the lecithin : cholesterol acyltransferase activity in the plasma of patients with diabetes mellitus. Fielding and coworkers (13) described decreased activity of lecithin : cholesterol acyltransferase in diabetics, whereas Schernthaner et al. (14) found normal activity. Gugliucci et al. (15) reported that $10-15 \%$ glycation of lysine residues in apolipoprotein A-I produces a $40 \%$ decrease in lecithin : cholesterol acyltransferase activation, compared with the control. In the present study, differences in the reactivity of lecithin : cholesterol acyltransferase with glycated apolipoprotein A-I become measurable when the degree of glycation of lysine residues reached $3-5 \%$.

An important consideration in studies of lecithin : cholesterol acyltransferase activity is the use of appropriate kinetic parameters to compare the reactivities of different substrates. In this report the ratio, apparent $\mathrm{V}_{\max }$ /apparent $K_{\mathrm{m}}$, was used to monitor the response of the enzyme to different substrates, after interaction of the enzyme with various concentrations of apolipoprotein A-I.

Studies using a series of native and synthetic fragments of apolipoprotein A-I support the concept that the interaction of the protein with lipids is of prime importance for this activating capacity of apolipoprotein A-I $(11,16,17)$. Lecithin : cholesterol acyltransferase does not require apolipoprotein to bind to lipid interfaces; however, on a pure lipid surface the active site may not be accessible to the lipid substrates (18). When apolipoprotein is present, the access of substrates to the active site may be facilitated by a direct interaction of the enzyme with the protein cofactor, or by an activation of the lipid substrates via the protein cofactor. It is possible that the glycation of lysine may cause a disruption in the relationships - of some portions of the apolipoprotein A-I structure. Studies of lecithin : cholesterol acyltransferase activation by synthetic peptides have led to the proposal that the major lecithin : cholesterol acyltransferaseactivating domain of apolipoprotein A-I resides in the 22 mer tandem repeats, located between residues 66 and 121 of the native apolipoprotein (19). Therefore, additional studies will be required in order to identify the preferential site of non-enzymatic glycation in apolipoprotein A-I, and to establish whether this involves amino acid residues that are specifically required in lecithin : cholesterol acyltransferase activation.

The significance in vivo of this decreased lecithin : cholesterol acyltransferase activation by glycated apolipoprotein A-I remains to be established. Because lecithin : cholesterol acyltransferase provides a driving force in reverse cholesterol transport by esterifying the cellular cholesterol removed by high density lipoproteins, it is possible that this abnormal activation may be associated with a reduction in reverse cholesterol transport and with the accelerated development of atherosclerosis in patients with diabetes mellitus.

\section{Acknowledgements}

This work was supported by grant 90-0274 from FONDECYT, and by grant 20.72.04 from the University of Concepción, Chile. 


\section{References}

1. Brewer, H. B., Fairwell, T., La Rue, A., Houser, A. \& Bronzert, T. J. (1978) The amino acid sequence of human apo A-I, an apolipoprotein isolated from high density lipoproteins. Biochem. Biophys. Res. Commun. 80, 623-630.

2. Fielding, C. J., Shore, V. G. \& Fielding, P. E. (1972) A protein cofactor of lecithin : cholesterol acyltransferase. Biochem. Biophys. Res. Commun. 46, 1493-1498.

3. Ponsin, G., Gotto, A. M., Utermann, G. \& Pownall, H. J. (1985) Abnormal interaction of the human apolipoprotein A-I variant (Lys $107 \rightarrow 0$ ) with high density lipoproteins. Biochem. Biophys. Res. Commun. 133, 856-862.

4. Rall, S. C., Weisgraber, K. H., Mahley, R. W., Ogawa, Y., Fielding, C. I., Utermann, G., Haas, J., Steinmetz, A., Menzel, H. J. \& Assmann, G. (1984) Abnormal lecithin : cholesterol acyltransferase activation by a human apolipoprotein A-I variant in which a single lysine residue is deleted. J. Biol. Chem. 259, 10063-10070.

5. Utermann, G., Haas, I., Steinmetz, A., Paetzold, R., Rall, S. C., Weisgraber, K. H. \& Mahley, R. M. (1984) Apolipoprotein A-I Giessen (Pro ${ }^{143} \rightarrow$ Arg). A mutant that is defective in activating lecithin : cholesterol acyltransferase. Eur. J. Biochem. 144, 325-331.

6. Calvo, C., Ponsin, G. \& Berthezene, F. (1988) Characterization of the non enzymatic glycation of high density lipoprotein in diabetic patients. Diabete \& Metab. 14, 264269.

7. Calvo, C., Talussot, C., Ponsin, G. \& Berthezene, F. (1988) Nonenzymatic glycation of apolipoprotein A-I. Effects on its self-association and lipid binding properties. Biochem. Biophys. Res. Commun. 153, 1060-1067.

8. Calvo, C. \& Verdugo, C. (1992) Association in vivo of glycated apolipoprotein A-I with high density lipoproteins. Eur. J. Clin. Chem. Clin. Biochem. 30, 3-5.

9. Havel, R. J., Eder, H. \& Bragdon, I. H. (1955) The distribution and chemical composition of ultracentrifugally separated lipoproteins in human serum. J. Clin. Invest. 34, 1345-1353.

10. Shepherd, J., Gotto, A. M., Jr. Taunton, O. D., Caslake, M. J. \& Farich, E. (1977) The in vitro interaction of human apolipoprotein A-I and high density lipoproteins. Biochim. Biophys. Acta 489, 486-501.
11. Soutar, A. K., Garner, C. W., Baker, H. N., Sparrow, J. T., Jackson, R. L., Gotto, A. M. \& Smith, L. S. (1975) Effects of the human plasma apolipoprotein and phosphatidylcholine acyl donor on the activity of lecithin : cholesterol acyltransferase. Biochemistry 14, 3057-3064.

12. Matz, C. E. \& Jonas, A. (1982) Micellar complexes of human apolipoprotein A-I with phosphatidylcholines and cholesterol prepared from cholate-lipid dispersions. J. Biol. Chem. 257, 4535-4540.

13. Fielding, C. J., Reaven, G. M. \& Fielding, P. E. (1982) Human noninsulin dependent diabetes: Identification of a defect in plasma cholesterol transport normalized in vivo by insulin and in vitro by selective inmunoadsorption of apolipoprotein E. Proc. Natl. Acad. Sci. USA 79, 63656369.

14. Schernthaner, G., Kostner, G, M., Dieplinger, H., Prager, R. \& Mühlhauser, I. (1983) Apolipoproteins (A-I, A-II, B), Lp (a) lipoprotein and lecithin : Cholesterol acyltransferase activity in diabetes mellitus. Atherosclerosis 49, 277-293.

15. Gugliucci, A. \& Stahl, A. J. C. (1991) In vitro glycation of human apolipoprotein A-I reduces its efficiency in lecithin : cholesterol acyltransferase activation. Clin. Chim. Acta 204, 37-42.

16. Pownall, H. J., Hu, A., Gotto, Jr. A. M., Albers, J. J. \& Sparrow, J. T. (1980) Activation of lecithin : cholesterol acyltransferase by a synthetic model lipid-associating peptide. Proc. Natl. Acad. Sci. USA 77, 3154-3158.

17. Pownall, H. J., Gotto, Jr. A. M. \& Sparrow, J. T. (1984) Thermodynamics of lipid-protein association and the activation of lecithin : cholesterol acyltransferase by synthetic model apolipopeptides. Biochim. Biophys. Acta 793, 149156.

18. Jonas, A. (1991) Lecithin : cholesterol acyltransferase in the metabolism of high density lipoproteins. Biochim. Biophys. Acta 1084, 205-220.

19. Anantharamaiah, G. M., Venkatachalapathi, Y. V., Brouillette, C. G. \& Segrest, J. P. (1990) Use of synthetic peptide analogues to localize lecithin : cholesterol acyltransferase activating domain in apolipoprotein A-I. Arterioslcerosis $10,95-105$.

Prof. Dr. Carlos Calvo

Departamento de Bioquímica Clínica

e Immunología

Facultad de Farmacia

Universidad de Concepción

Casilla 237, Concepción

Chile 